\title{
INCERTEZAS DIANTE DO CANCER INFANTIL: COMPREENDENDO AS NECESSIDADES DA MÃE
}

\author{
Uncertainties in the childhood cancer: understanding the \\ mother's needs \\ Incertidumbre frente al cáncer infantil: entender las \\ necesidades de la madre
}

Margareth Angelo ${ }^{1}$

Patrícia Luciana Moreira ${ }^{2}$

Laura Maria Alves Rodrigues 3

\section{RESUMO}

Os objetivos deste estudo foram identificar as necessidades da mãe durante a internação do filho com câncer e compreender como as incertezas diante da doença configuram-se nesta experiência. 0 referencial teórico do estudo foi o Interacionismo Simbólico e o referencial metodológico, o Interacionismo Interpretativo. A coleta de dados foi conduzida por meio de entrevistas semiestruturadas. Participaram do estudo 10 mães de crianças hospitalizadas em uma instituição especializada no município de São Paulo. Foram identificadas três categorias descritivas das necessidades experienciadas pelas mães: (1) Necessidade de estar presente e acompanhar o tratamento; (2) Necessidade de ser amparada nos momentos de fraqueza; (3) Necessidade de manter vínculo com a família. As necessidades da mãe durante a internação da criança com câncer têm caráter multidimensional, e 0 reconhecimento delas é essencial para garantir a criação de um contexto de cuidado que potencialize o papel da mãe no suporte à criança com câncer.

Palavras-chave: Mães. Criança Hospitalizada. Neoplasias. Incerteza.

\begin{abstract}
The objectives of this study were to identify the mother's needs during the hospitalization of the child with cancer and understand how the uncertainties in the disease shape up in this experience. The theoretical framework of the study was the symbolic interactionism and the methodological framework, the interpretative interactionism. The data were obtained by semistructured interviews. ten (10) mothers, whose children were hospitalized in a specialized institution in são paulo, participated of the study. We identified three categories that describe the mother's needs: 1) need of being with and follow the treatment; 2) need of being supported during weakness; 3 ) need to maintain ties with the family. The mother's needs during the hospitalization of the child with cancer have multidimensional character and its recognition is essential to guarantee the creation of a context that raises the mother's function supporting the child with cancer.
\end{abstract}

Keywords: Mothers. Hospitalized child. Neoplasms. Uncertainty

\section{Resumen}

Los objetivos de este estudio fueron identificar las necesidades de la madre durante la internación del hijo con cáncer y comprender como la incertidumbre frente a la enfermedad se ubican dentro de esta experiencia. El marco teórico del estudio fue el Interaccionismo Simbólico y el marcol metodológico, el Interaccionismo Interpretativo. La recolección de datos se llevó a cabo a través de entrevistas semiestructuradas. Participaron del estudio 10 madres de niños internados en una institución especializada en la ciudad de São Paulo. Se identificaron tres categorías descriptivas de las necesidades vividas por las madres: (1) Necesidad de estar presente y estar al pendiente del tratamiento; (2) Necesidad de apoyo en los momentos de la debilidad; (3) Necesidad de mantener el vínculo con la familia. Las necesidades de la madre durante la internación del niño con cáncer tienen carácter multidimensional y el reconocimiento de los mismos es fundamental para garantizar la creación de un ambiente de cuidado que refuerce el papel de la madre en la apoyo al niño con cáncer.

Palabras clave: Madres. Ninõ hospitalizado. Neoplasias. Incertidumbre

\footnotetext{
Enfermeira, Professora Titular do Departamento de Enfermagem Materno-Infantil e Psiquiátrica da Escola de Enfermagem da Universidade de São Paulo. Brasil. Email: angelm@usp.br, ${ }^{2}$ Enfermeira, Mestre em Enfermagem Pediátrica pelo Programa de Pós-Graduação da Escola de Enfermagem da Universidade de São Paulo. Brasil. Email: patriciamoreira@yahoo.com, ${ }^{3}$ Enfermeira graduada pela Escola de Enfermagem da Universidade de São Paulo. Enfermeira assistencial - Unidade de Terapia Intensiva do INCOR-HCFMUSP. Especialista em cardiologia pelo programa de aprimoramento de pessoal do INCOR-HC FMUSP. Brasil. E-mail : rodrigues_lau@hotmail.com
} 


\section{INTRODUCÃO}

A experiência de ter um filho com câncer ocasiona diversos efeitos na vida da família; a necessidade de aproximação, dificuldades financeiras, sacrifício, dor e angústia emocional são alguns deles. A sensação é de estar vivenciando uma luta, na qual os pais questionam o porquê da doença em suas vidas. 0 impacto da doença faz com que cada membro da família desenvolva novas habilidades e tarefas no cotidiano familiar para resolver os conflitos em função da hospitalização e das demandas da doença nos aspectos físicos, psicossociais e financeiros. ${ }^{1-2}$

Quando uma criança tem o diagnóstico de câncer, é frequente a mãe aprender rapidamente a lidar com os aspectos médicos da doença e com as necessidades e medo dos membros da família. Assim, ela é vista como a principal pessoa no cuidado da criança doente. ${ }^{3}$ As mães experienciam e vivenciam muito de perto o processo da doença, que se inicia com a notícia de que algo não vai bem com a criança e se concretiza com o diagnóstico. 0 diagnóstico de câncer na infância traz consigo uma significativa crise na família, sendo um momento de transição, de definir e redefinir os papéis de mães. ${ }^{4}$

Ser mãe de uma criança com câncer é viver uma experiência mediada pela construção de um novo papel, permeado pelo seu dever, pelo tempo como mãe que está ameaçado pela doença, pelo significado que ela atribui ao câncer. As dimensões de ser mãe nesta situação, objeto de outro estudo que realizamos, ${ }^{5}$ ultrapassam as dimensões do cuidado, expressando-se por comportamentos e ações mediadas pelo tempo e pela necessidade de afastar a possibilidade de perder a criança. As inúmeras transformações que se instalam na situação de doença fazem com que a mãe passe a desenvolver estratégias para lidar com o novo contexto e suas exigências, representando um estímulo para que se sinta capaz e disponível à aprender. Dentre as habilidades e os mecanismos desenvolvidos estão a paciência, a coragem e a força interior para superar as incertezas quanto ao futuro. ${ }^{6}$

Vivendo entre a esperança e o medo, a incerteza tem um profundo impacto na experiência da família da criança com câncer, na busca pela cura, nas tomadas de decisão mediante o tratamento e prognóstico. ${ }^{7}$ A perda faz parte do mundo variável e inconstante das famílias e o insuperável e maior medo que vivenciam é a perda da criança doente. A família percebe que a vida nunca mais seria a mesma depois do câncer e reconhece todas as novas e significativas perdas, tentando manter o espírito vivo e mover-se adiante para alcançar 0 objetivo de uma diferente jornada de vida, que não foi parte do seu plano original. ${ }^{8} \mathrm{~A}$ incerteza está vinculada estreitamente com a insegurança vivenciada pela mãe durante o tempo de batalha contra o câncer do filho. Sendo ele sua prioridade neste tempo, a confiança estabelecida com a instituição e com os profissionais proporcionam-lhe a segurança para prosseguir a trajetória e enfrentar as demandas da doença. A segurança não somente é uma busca da mãe para desempenhar seu papel, mas também para ser transmitida para a criança nos momentos difícies da convivência com o câncer. ${ }^{5}$

Sabemos que a literatura traz evidências sobre os sentimentos da mãe na situação do câncer do filho, ${ }^{1,3,5,9}$ mas em nosso meio esta relação da experiência diante da incerteza não tem sido explorada. Considerando que a hospitalização é uma necessidade frequente no tratamento do câncer, interessou-nos compreender melhor algumas dimensões do ser mãe na experiência de acompanhar a internação do filho com câncer e como as incertezas vivenciadas por ela revelamse na situação de hospitalização da criança. Desta forma, as perguntas que ancoraram nossas inquietações foram: quais são as necessidades das mães que acompanham o filho com câncer durante a internação? Como as incertezas vivenciadas pela mãe diante da doença do filho na situação de hospitalização se configuram na experiência do câncer? Acreditamos que este conhecimento pode contribuir para que alguns comportamentos da mãe sejam mais bem compreendidos na situação de hospitalização do filho. Além disso, contribuirá para que a assistência de enfermagem à mãe que acompanha integralmente o filho hospitalizado possa suprir suas necessidades por meio de intervenções mais efetivas e que minimizem suas incertezas e seu sofrimento. Assim, os objetivos deste estudo foram identificar as necessidades da mãe durante a internação da criança com câncer e compreender como as incertezas diante da doença configuram-se nesta experiência

\section{METODOLOGIA}

Referencial teórico: o Interacionismo Simbólico foi o referencial teórico deste estudo, cujas ideias centrais baseiam-se no processo de interação, no qual os indivíduos são ativos e atribuem significados às coisas e às suas experiências. Nesta perspectiva, o significado é um processo interacional e interpretativo, no qual o indivíduo é ator e reator neste processo, imprevisível no mundo. ${ }^{10}$

Referencial metodológico: este estudo qualitativo foi guiado pelos passos do Interacionismo Interpretativo ${ }^{11}$, que tem como foco a interpretação como um processo que segue em busca do significado de um evento ou experiência. No processo interpretativo do referencial está presente uma 
tríade, ou seja, uma pessoa, um objeto ou evento, e a ação tomada com relação a este objeto ou evento. Este método procura ver o mundo e seus problemas como eles são vistos pelas pessoas que vivem no interior deste mundo, não somente descrevendo-o, mas trazendo também os pensamentos e sentimentos que tornam o mundo vivo. Para tanto, acessa a descrição densa, biográfica, histórica, situacional e interacional, que permite desvendar o significado da experiência das pessoas e o subsídio para o processo interpretativo. ${ }^{11}$

Local da pesquisa: a pesquisa foi realizada no Instituto de Oncologia Pediátrica (IOP) - Grupo de Apoio ao Adolescente e à Criança com Câncer (GRAACC), vinculado à Universidade Federal de São Paulo (UNIFESP), localizado no município de São Paulo. A instituição atende crianças e adolescentes com câncer, sendo um centro de referência para este tipo de assistência. Conta com equipe interdisciplinar e possui, entre outros serviços, ambulatório de quimioterapia, centro cirúrgico, unidade de terapia intensiva e unidade de internação, setor no qual foram realizadas as entrevistas.

Participantes do estudo: participaram do estudo 10 mães de crianças em tratamento oncológico que estavam hospitalizadas, sendo este o critério de inclusão. Não foram considerados como critérios de seleção a idade da criança, o tipo de câncer, o tempo de tratamento ou o motivo da internação. A idade das mães participantes variou entre 24 e 57 anos na ocasião da entrevista, sendo uma solteira, duas divorciadas e sete casadas. Nove dessas mães tinham outros filhos, além do filho que estava hospitalizado. Três mães trabalhavam e duas mencionaram que pararam de trabalhar após o diagnóstico. 0 número de mães participantes não foi determinado a priori. A coleta de dados foi interrompida quando os dados começaram a se tornar repetitivos.

Coleta de dados: a coleta de dados foi orientada pela estratégia de entrevista do tipo semiestruturada, que permite investigar a experiência da pessoa em determinado momento de sua vida, a partir de narrativas seguindo a seguinte solicitação: "por favor, descreva sua experiência em relação à hospitalização de seu filho e o que a senhora precisa para se sentir segura cuidando de seu filho aqui no hospital". As narrativas foram gravadas e transcritas na íntegra para serem submetidas a análise.

Análise dos dados: a análise das narrativas foi conduzida de acordo com os quatro primeiros passos do Interacionismo Interpretativo ${ }^{9}$ que são: desconstrução, apreensão, redução e construção. Cada narrativa foi subdividida em pequenas unidades experienciais caracterizadas por pequenas frases-chave. Cada frase-chave foi interpretada e os seus significados, depois de identificados, foram conectados a outras frases-chave dentro da história. Esta conexão entre os significados possibilitou o agrupamento das frases que possuiam significados semelhantes nas narrativas das mães. Assim, durante 0 processo de análise foi dada ênfase ao conteúdo semântico de palavras e evidências fornecidas pelas mães, relativas às suas experiências e necessidades. Após o procedimento de caráter analítico, o material interpretado foi organizado e deu origem a categorias que permitiram uma descrição densa da experiência estudada.

Aspectos éticos: para garantir os direitos das participantes, foram observados todos os aspectos presentes na Resolução CNS 196/96. 0 projeto foi submetido à apreciação e aprovação do Comitê de Ética em Pesquisa da Escola de Enfermagem da Universidade de São Paulo, certificado sob Processo n ${ }^{\circ}$ 453/2005/CEP-EEUSP, de 30 de junho de 2005, e autorizado pela Instituição selecionada. Uma vez selecionadas as participantes, foram fornecidas as informações oralmente e por escrito sobre os objetivos e forma de participação na pesquisa. Procurou-se ressaltar que a participação era voluntária e a possibilidade da interrupção dessa participação em qualquer etapa do estudo, sem qualquer prejuízo. Foram garantidos também o anonimato das participantes, o respeito e a confidencialidade das informações fornecidas aos pesquisadores. A entrevista foi realizada após a aceitação da mãe em participar do estudo, formalizada pelo Termo de Consentimento Livre e Esclarecido.

\section{RESULTADO}

No processo de análise, três categorias de necessidades das mães foram identificadas, mostrando-se articuladas a todo o contexto do câncer e da incerteza experienciada pela mãe no processo de tratamento, e não apenas ao tempo da internação. Além do desconhecimento sobre a doença, que ocorre em fases iniciais da experiência, a incerteza envolve dimensões de indecisão, dúvida e insegurança ao longo de todo o processo, no qual 0 atendimento às necessidades identificadas corresponde a um elemento fundamental na experiência de segurança da mãe. A incerteza, somada à convicção de que precisa fazer o que estiver ao seu alcance para proteger a vida do filho, configura-se como o contexto experiencial no qual as necessidades se manifestam. Apresentaremos a descrição das categorias e trechos de narrativas que retratam a experiência descrita. A fim de garantir o sigilo das participantes, utilizaremos nesses a sigla $\mathrm{E}$, seguida de um número, correspondente à ordem de realização das entrevistas. 
1) Necessidade de estar presente e acompanhar o tratamento

Como um componente que se destaca diante da insegurança, estar presente e acompanhar o tratamento do filho representa segurança para a mãe e também para a criança. A necessidade de estar ao lado do filho, transmitindo-lhe força e segurança é fundamental. Para tanto, a presença no processo de tratamento é composta por algumas demandas destinadas a preparar a mãe para uma presença efetiva. Entender para poder ajudar é uma necessidade para se sentir mais segura, para aumentar sua autoconfiança. Isso se soma ao objetivo de ajudar o filho, pois a incerteza presente na trajetória do câncer envolve indecisão e perda da segurança. Há uma busca de autofor talecimento, de sentir-se preparada para a difícil situação vivida, muitas vezes resultado da iniciativa da própria mãe, que vai ao encontro das informações que necessita.

O que eu faço é ter mais orientação, procuro ler muito, procuro pesquisar a parte dele, sobre o câncer que ele tem, agora que ele tirou os dois rins... tudo isso eu pesquiso, leio muito. Não fico só parada. Aí eu quero saber sobre o medicamento que ele vai tomar, porque que ele está dormindo mais, porque que ele ganhou mais peso, tudo isso eu procuro saber muito. (E4)

A mãe, nessa busca por conhecer e entender o que se passa, necessita sentir segurança nos médicos e na equipe. Ela precisa confiar em quem está cuidando ou tratando do seu filho. No ambiente hospitalar, ela observa a competência e a interação das pessoas, procurando, com isso, compreender o que está acontecendo e ir estabelecendo uma relação de confiança com os profissionais.

O que eu preciso é só a segurança dos médicos. Se eu sentir segurança nos médicos e firmeza no tratamento, fico segura. As intercorrências vão vir, a gente sabe; é uma doença agressiva. Mas só isso: se eu sentir segurança no tratamento, a gente também fica tranqüila. (E1)

Grande parte da segurança vem do relacionamento com os profissionais dos quais espera receber informaç̧̃es sem omissão de fatos, ficando atenta à transparência dessas informações. A mãe não sabe o que esperar e, dependendo do que lhe for orientado, alimentará a esperança ou se preparará para lidar com a dor e com as possíveis perdas. A incerteza decorrente da convivência com o desconhecido está intimamente relacionada com a insegurança da mãe durante a hospitalização, não permitindo planejar o cotidiano e o futuro próximo. A mãe precisa de informações concretas para se apoiar e inserir aquela experiência em sua vida e na vida de sua família.

Então o que faz a gente ficar mais segura é isso: eles passarem isso pra gente, entendeu? Dar uma palavra, "eu não vou te enganar". Então, isso aífaz você ficar segura, éisso. Falar a verdade, embora doa, mas eles estão ali dizendo à mãe que a filha está assim, assim, assim, né? Se tiver bem eles falam que está bem, se tiver ruim eles falam que está ruim e isso é bom pra nós. Porque a gente, vamos supor, se ainda vier a acontecer o caso delas virem, até mesmo que dói, elas virem fechar os olhos, nós não estamos sendo enganadas... É duro quando a verdade é escondida, e aí a gente fica revoltada. Mas quando eles falam, a realidade, a verdade, ... Aiébom. (E5)

2) Necessidade de ser amparada nos momentos de fraqueza

Sentir que está sendo uma boa mãe na situação da doença é vital, pois envolve ter competência para atender as demandas do filho e um certo controle do que se passa ao longo do processo. Entretanto, esta é uma luta que a mãe enfrenta apesar de nem sempre se sentir equipada para prosseguir no que acredita ser seu papel. Para poder estar presente ao lado do filho no hospital, a mãe precisa de apoio e sentir que não está sozinha nessa batalha. Ela se sente mais segura à medida que se percebe inserida na equipe que cuida de seu filho, pertencendo a um contexto relacional que tem 0 mesmo objetivo: a cura e o cuidado do filho. Sentir-se acolhida pela equipe influencia positivamente em sua segurança. Ela tem a necessidade de um relacionamento que ultrapasse a visão fisiopatológica da doença e que considere a criança enquanto criança, inserida no ambiente familiar. A mãe identifica esse cuidado pela paciência, pelo olhar acolhedor, na forma de falarem com ela e com o filho. Quanto mais ela se sente acolhida e aceita, mais livre se sente para questionar e esclarecer suas dúvidas, bem como para desenvolver as competências de que necessita em cada fase do tratamento.

Ah... eu acho que o apoio que eles - os profissionais - têm que dar, né? Porque é um momento muito difícil, tem que ter muita paciência, tanto com as 
mães quanto com as crianças. E eu acho que isso também ajuda a gente a encarar melhor! (E9)

A gente conversa, as voluntárias dão muito apoio, são amigas, entendeu! Elas são muito amigas, conversam, tiram aquela angústia que você sente naquele momento. Isso ai que ajuda também entendeu? Ajuda. (E8)

0 apoio mútuo entre as mães, a troca de experiências, o consolo e a autoestima transmitida também são elementos que ajudam no enfrentamento da situação de doença e no fortalecimento da mãe. Algumas, inclusive, se fortalecem percebendo ser úteis às outras, ou seja, levando uma palavra amiga ou escutando, dando seu depoimento e relatando sua experiência de vida. No sofrimento, o fato de ver que há pessoas que compartilham a mesma situação de dor e angústia ajuda no ressurgimento da esperança que começara a se perder, sendo um estímulo para continuar a lutar.

Enquanto eu não pegar todos os dias e não for em cada quarto, pra mim, está faltando alguma coisa. Eu tenho, pelo menos que dizer pras mães um 'bom dia' e dizer que vai dar tudo certo. (...) Ou então, se ainda dá pra eu pegar algumas, que às vezes chegam umas mães mais tarde, aí eu tenho que ver essas mães, que às vezes eu acho que não importa o que se está passando, mas uma palavra, eu acho que vale muito. Eeujá vi muitas mães aqui, elas são uma bênção pra mime eu sou uma benção na vida delas também; a gente pode trazer a paz, que vai conseguir e vai dar tudo certo, eu passei a nossa experiência, é passar pra elas, écomo se diz: a experiência delas passa pra gente e a gente passa pra elas, e éo quefaz a gente manter firme; também se ajudar. Primeiramente Deus, segundo a gente estar indo dar o braço uma pra outra, pra unir... (E5)

Esta necessidade também envolve perceber o hospital como um ambiente familiar, já que o processo de tratamento é longo e a participação da mãe implica abrir mão de outros papéis que desempenhava antes da doença. Identificar os recursos para as demandas da doença lhe garantem o amparo para permanecer em período integral ao lado do filho durante a internação. Além disso, a mãe também precisa buscar apoio na fé, em "algo" que transcenda suas forças e o apoio das pessoas, pois tem consciência das suas limitações e fraquezas, para que não desista.
O que vai me ajudar... eu continuar com fé porque sem fé, acho que dava pra desistir porque o tratamento é tão doido, tão agressivo! Mas vai dar tudo certo, eu creio. Mais uma vez, deu a primeira, deu a segunda, deu a terceira e vai dar a quarta de novo, eu creio. (E7)

A existência de um local onde se possa sentir ancorada nos momentos de fragilidade tem um significado de amparo nos momentos nos quais a mãe sente suas forças fraquejarem. Um local calmo e reservado onde possa exercitar a espiritualidade, um "ambiente acolhedor" ou um local que a mãe procura para refazer suas forças, desabafar e reencontrar a esperança. Chorar longe do filho é uma demanda da mãe e mostra mais uma vez o conhecimento da própria fraqueza e limitação e, ao mesmo tempo, uma consciência de que precisa ser forte e passar essa força para a criança.

Então, pra ele, eu tenho que ser forte. Eu não tenho essa força, mas pra ele eu preciso mostrar essa força. Então, na hora que me dá vontade de chorar eu vou para dentro do banheiro, eu vou para o cantinho da paz entendeu? Porque chega uma hora que você quer, mas éo que eu falo, não tem... é Deus que está me dando a força de aguentar o que eu aguento. Vem de Deus essa força porque eu não... Deus me ensinou a viver a cada momento; o hoje, você vive, o amanhã pertence a Ele. (E10)

3) Necessidade de manter vínculo com a família

Embora o foco principal da mãe seja o filho com câncer, ela continua sendo mãe de outros filhos, e assim, tenta conciliar as necessidades de todos. 0 contato com os outros membros da família, no contexto do câncer, fica muitas vezes prejudicado, em função dos frequentes e longos afastamentos do domicílio para possibilitar o tratamento. Esta demanda da mãe é uma forma de garantir para si mesma que não está abandonando os demais membros da família, ao mesmo tempo em que esta proximidade também lhe garante 0 apoio e segurança de que necessita.

Então, na hora que eu vejo que estou caindo, ele (o marido) me passa essa segurança, ele me passa um jeitinho, entendeu, alegre e faz eu ... eu me erguer um pouco. (E7) 
0 apoio e a compreensão da família proporcionam para a mãe, que teve que sair de casa para se dedicar exclusivamente ao filho na situação de hospitalização, a força impulsionadora para prosseguir sua trajetória. Além disso, a família também tem um potencial para aliviar a carga da mãe, compartilhando responsabilidades, na medida em que participam do cuidado da criança. A mãe que não tem esse apoio enfrenta uma lacuna de apoio essencial para o suporte que precisa ter na experiência de acompanhar um filho com câncer. Torna-se difícil para a mãe manter a unidade familiar pela sua ausência física no ambiente de casa. Muitas vezes, a mãe percebe-se tendo que fazer escolhas, estabelecendo como prioridade o que corre mais risco: a vida do filho com câncer. Em função disso, outras atividades têm um papel coadjuvante na manutenção do vínculo com a família e no exercício do seu papel de mãe dos demais filhos.

Olha, eu tenho que chegar em casa e tenho que ouvir tudo o que eles querem que eu ouça, querem me mostrar, eu tenho que parar pra ver, eu pego, quando eu vou pra casa eu pego brinquedo da brinquedoteca, eu peço permissão pra levar, então eu levo "CD", eu levo joguinho, eu levo para brincar junto com eles... Eu tento suprir desta forma, entendeu? Mas às vezes étão pouco tempo, quando ele está internado. Agora, quando, quando ele não está internado, é... que ele vai e volta, émeu esposo que traz ele, aí eu ajo na minha vida lá normal, entendeu? (E10)

As categorias descritas permitem compreender 0 universo da mãe que vive a experiência de ter um filho com câncer, por meio de suas necessidades, que confluem para o fato de a mãe precisar sentir-se segura, preparada e forte para lidar com os desafios do processo da doença.

\section{DISCUSSÃO}

As necessidades identificadas neste estudo abordam as necessidades físicas, sociais, cognitivas, afetivas e comportamentais vivenciadas pela mãe na situação de hospitalização do filho em tratamento oncológico. Estes resultados são coerentes com estudos da literatura nacional e internacional. 0 diagnóstico de câncer da criança traz um conjunto de novas responsabilidades e papéis, incluindo a obrigação da proximidade, de estar fisicamente próxima do filho para proporcionar conforto e estar vigilante. Para a mãe, cuidar do filho com câncer evoca uma intensa interdependência emocional com a criança doente e envolve uma gama de tarefas, incluindo agir como mediadora da informação para a criança e conseguir cooperar no tratamento. ${ }^{4}$ A mãe procura estar próxima do filho, estabelecendo uma relação de proximidade durante todos os momentos da trajetória da doença, inclusive os de internação. ${ }^{5}$

A literatura acerca das necessidades dos pais de crianças com câncer durante a hospitalização revela que elas têm um caráter multidimensional. Dentre as dimensões, destaca-se em diversos estudos a necessidade de obter informação, seja sobre a doença, o prognóstico, plano terapêutico ou sobre as condições da criança., ${ }^{9,12} \mathrm{Em}$ comparação com os nossos resultados, estudos revelaram que a busca por conhecer sobre a doença é uma forma de preparação da mãe para se sentir mais forte, confiante e preparada para cuidar do filho hospitalizado, sabendo lidar com os eventos inesperados e com a incerteza gerada pela doença. A necessidade de informação revela-se como um elemento fundamental para a mãe durante a hospitalização da criança. A mãe demostra que é um ser ativo neste contexto, buscando informações, questionando a equipe, solicitando ajuda e preparando-se para ser informada sobre o estado da criança. Neste sentido, a incerteza emerge em contraponto à seguranç̧a, considerada pela mãe como algo fundamental para assumir o tratamento junto ao filho e todas as suas demandas.

Recente estudo em nosso meio mostrou que a incerteza decorrente do câncer do filho revela-se por meio de sentimentos e ações que são vivenciadas pela família nas interações que estabelece no contexto da doença. Não saber o que esperar ou o que pode acontecer reflete o medo da perda e a impotência diante do sofrimento do filho. ${ }^{13}$ Concordamos que a incerteza experienciada é uma condição dinâmica que pode variar dentro de cada família, sendo, portanto, complexa. Compreender os fatores envolvidos com a incerteza é um subsídio para que os profissionais ajudem as mães a lidar com a situação. Existem vários estágios de incerteza, que dependem de situações como informação do diagnóstico, repetição de procedimentos invasivos, possibilidade da morte e hospitalização. A incerteza foi associada à sensação de conviver com o desconhecido e de não saber o que esperar. Os enfermeiros e outros profissionais precisam informar as famílias sobre todas as condições da doença da criança e considerar também o momento de informar. No entanto, é necessário fazê-lo de uma maneira em que se considerem as necessidades particulares de cada família. ${ }^{14}$

Um estudo identificou que os pais precisam de muitas informações sobre a condição clínica do seu filho, mostrando que existem dúvidas experienciadas por eles que os profissionais devem procurar esclarecer. Ao mesmo tempo, os pais solicitam uma informação transmitida com termos 
compreensíveis, que lhes capacite a participar do cuidado e da tomada de decisão. ${ }^{15}$ Participar do cuidado envolve,,, além da presença física da mãe ao lado da criança, a compreensão do que se passa, a confiança na equipe responsável por seu filho e sentir-se integrada a essa equipe, sendo aceita e valorizada pelos profissionais. Nos relatos das mães analisados neste estudo foi possível identificar os mecanismos utilizados por elas para conseguirem conviver com a incerteza e, ao mesmo tempo, tentar transmitir segurança ao filho, sentindo-se ela mesma segura em relação ao cuidado. 0 fortalecimento revelado pela mãe é, muitas vezes, proveniente da busca de conforto na religião e na fé e da procura de apoio nas outras mães, profissionais e voluntárias do serviço. As mães buscam esse apoio para não se sentirem sozinhas nessa batalha. Esta é uma maneira que elas encontram para suprir a necessidade de amparo na situação de hospitalização e incer teza mediante a doença do filho. Um estudo mostra que pais de crianças com câncer obtêm esperança e sentem-se mais conformados não só pelo fato de o tratamento estar fazendo sucesso, mas também pelo contato com os profissionais de saúde e com as famílias de outras crianças hospitalizadas. ${ }^{16}$

0 suporte da família, dos amigos e de outras mães com experiências similares destaca-se como um apoio importante para as mães durante a hospitalização. Compartilhar os sentimentos com outras mães que vivenciam situações semelhantes, buscando amparo e consolo, acaba fornecendo segurança e ajuda a mãe a lidar com a incerteza gerada pelo diagnóstico e tratamento, sendo um estímulo para continuar a lutar. Essas características foram estudadas em famílias rurais cujo filho recebera o diagnóstico de câncer e configuraram-se como um auxílio encontrado pelas famílias para a readaptação de sua vida às novas circunstâncias impostas pela doença. ${ }^{17} \mathrm{Um}$ estudo realizado com famílias chinesas identificou o suporte dado pela família, tanto o emocional quanto o financeiro, como um auxílio de relevância para os pais durante o período de hospitalização da criança. ${ }^{13}$ Além da necessidade de sentir-se apoiada, a mãe também tem a necessidade de garantir para si mesma que não está abandonando os demais membros da família. 0 conflito entre a necessidade de estar presente e junto ao filho em tratamento e continuar cumprindo seu papel de mãe dos outros filhos é vivenciado pela mãe com significativo sofrimento. Evidências mostram, assim como nosso estudo, que mães de crianças com câncer encontram dificuldades para manejar a necessidade entre proporcionar o cuidado ao filho doente e coordenar, organizar, estruturar e planejar atividades para a família. ${ }^{18}$

Assim, percebemos a importância de que os profissionais compreendam as mães das crianças com câncer e as ajudem a encontrar significados que contribuam para 0 enfrentamento da situação, mesmo diante da incerteza do tratamento. É fundamental que as mães tenham segurança para assumir seu papel na complexa trajetória do câncer, sendo este em grande parte proporcionado pelas interaç̃̃es que se estabelecem com a instituição e os profissionais que cuidam do seu filho.

Este estudo teve como foco as necessidades da mãe durante a hospitalização do filho com câncer e como as incertezas configuram-se nesta experiência. Os resultados deste estudo estão limitados a um pequeno número de entrevistas. Embora os resultados não possam ser generalizados a outros contextos, eles possibilitam novas reflexões para potencializar os princípios do cuidado centrado na família no contexto do cuidado à criança com câncer. As evidências deste estudo mostram que as necessidades da mãe não estão desvinculadas das necessidades da criança e da família. Assim, novos estudos devem ser realizados focalizando as necessidades da própria criança com câncer e dos demais membros da família em função das demandas especíicas do período de internação. Acreditamos que é importante a realização de pesquisas que abordem a relação entre incerteza e segurança no contexto da hospitalização. Em nosso estudo e na literatura, a incerteza e a segurança são componentes da experiência no contexto da hospitalização durante 0 tratamento oncológico. É fundamental que o reconhecimento destes componentes seja consistente para planejamento de uma assistência efetiva às necessidades da mãe, da criança e da família que vivenciam a complexa trajetória do câncer infantil e suas demandas.

\section{CONSIDERAÇÕES FINAIS}

Este estudo revelou aspectos da incerteza e insegurança, do amparo e do vínculo vivenciados pela mãe da criança com câncer ao revelar suas necessidades durante a hospitalização do filho. Neste contexto, revelou um conjunto de necessidades da mãe durante a internação, que têm caráter multidimensional e demandam atenção da equipe multiprofissional. 0 reconhecimento da necessidade pode garantir a criação de um contexto de cuidado que potencialize o papel da mãe no suporte à criança no processo da doença $\mathrm{e}$ que ajude a mãe a atribuir um sentido à experiência de ter um filho com câncer. Sabemos que a incerteza e a insegurança são elementos constantes na oncologia e que o resultado final da experiência não está apenas no êxito do tratamento e na obtenção da cura da criança, mas também na maneira como cada etapa do processo foi vivida. Os profissionais e todas as 


\section{Incertezas diante do Câncer infantil}

Angelo M, Moreira PL, Rodrigues LMA pessoas que partilham da experiência com a mãe podem influir neste resultado, conforme suas atitudes e ações diante das necessidades manifestadas ao longo do tratamento, podendo auxiliar ou prejudicar o fortalecimento da mãe para incorporar o evento câncer na sua vida e na vida da família. Finalmente, acreditamos que é preciso ouvir o que nos dizem as mães que vivenciam junto com o filho a experiência do câncer.

\section{REFERÊNCIAS}

1 - Dixon-Woods M, Seale C, Young B, Heney D. Representing childhood cancer: accounts from newspaper and parents. Soc Health IIIness. 2003; 25(2): 143-64.

2 - Silva FAC, Andrade PR, Barbosa TR, Hoffmann MV, Macedo CR. Representação do processo de adoecimento de crianças e adolescentes oncológicos junto aos familiares. Esc Anna Nery Rev Enferm 2009; 13(2): 334-41.

3 - Clarke JN, Fletcher PC, Schnider MA. Mothers' home health care work when their children have cancer. J Pediatr Oncol Nurs 2005; 22(6): 265-73.

4 - Young B, Dixon-Woods M, Findlay M, Heney D. Parenting in a crisis: conceptualising mothers of children with cancer. Soc Sci Med 2002; 55(10): 1835-847.

5 - Moreira PL, Angelo M. Tornar-se mãe de criança com câncer: construindo a parentalidade. Rev Latino-am Enfermagem 2008; 16(3): 355-61.

6 - Almeida Ml et al. 0 ser mãe de criança com doença crônica: realizando cuidados complexos. Esc Anna Nery R Enferm 2006; 10(1): 36-46.

7 - De Graves S, Aranda S. Living with hope and fear - the uncertainty of childhood cancer after relapse. Cancer Nurs 2008; 31(4): 292301.

8 - Woodgate R. Life is never the same: childhood cancer narratives. Eur J Oncol Nurs 2006; 15(1): 8-18.

9 - Keegan-Wells D, James K, Stewart J, Moore K, Kelly K, Moore B, et al. The care of my child with cancer: a new instrument to measure caregiving demands in parents of children with cancer. J Pediatr Nurs 2002; 17: 201-10.

10 - Charon JM. Symbolic Interactionism. An introduction, an interpretation, an integration. New Jersey(USA): Prentice Hall; 1989.

11 - Denzin NK. Interpretative Interactionism. California(USA): SAGE Publications; 1989.

12 - Yiu JMC, Twinn, S. Determining the needs of Chinese parents during the hospitalization of their child diagnosed with cancer: an exploratory study. Cancer Nurs 2001; 24(6): 483-89.
13 - Cunha MLR. Incerteza e sacrifício: o sofrimento da vida familiar invadida pelo câncer da criança [tese]. São Paulo (SP): Escola de Enfermagem/ USP; 2009.

14 - Woodgate RL. "Nothing is carved in stone": uncertainty in children with cancer and their families. Eur J Oncol Nurs 2002; 6(4): 191-202.

15 - Patistea E, Batatsikou F. Parents' perceptions of the information provided to team about their child's leukemia. Eur J Oncol Nurs 2003; 7(3): 171-81.

16 - Azeredo Z, Amado J, Silva HNA, Marques IG, Mendes MVC. A família da criança oncológica: testemunhos. Acta Med Port. 2004; 17: 375-80.

17 - Scott-Findlay S, Chalmers K. Rural families' perspectives on having a child with cancer. J Pediat Oncol Nurs 2001; 18(5): 205-16.

18 - Svavarsdottir EK. Caring for a child with cancer: a longitudinal perspective. J Adv Nurs 2005; 50(2): 153-61. 